\title{
A binary logistic regression model with complex sampling design of unmet need for family planning among all women aged (15-49) in Ethiopia.
}

\author{
Demeke Lakew Workie, Dereje Tesfaye Zike, Haile Mekonnen Fenta, Mulusew Admasu Mekonnen
}

Department of Statistics, Bahir Dar University, Bahir Dar, Ethiopia

PMA2020/Ethiopia project, www.pma2020.org/Ethiopia

$\&$

John Snow Inc (JSI) SEUHP/Ethiopia project

\begin{abstract}
Background: Unintended pregnancy related to unmet need is a worldwide problem that affects societies. The main objective of this study was to identify the prevalence and determinants of unmet need for family planning among women aged (15-49) in Ethiopia.

Methods: The Performance Monitoring and Accountability2020/Ethiopia was conducted in April 2016 at round-4 from 7494 women with two-stage-stratified sampling. Bi-variable and multi-variable binary logistic regression model with complex sampling design was fitted.

Results: The prevalence of unmet-need for family planning was $16.2 \%$ in Ethiopia. Women between the age range of $15-24$ years were 2.266 times more likely to have unmet need family planning compared to above 35 years. Women who were currently married were about 8 times more likely to have unmet need family planning compared to never married women. Women who had no under-five child were 0.125 times less likely to have unmet need family planning compared to those who had more than two-under-5.

Conclusion: The key determinants of unmet need family planning in Ethiopia were residence, age, marital-status, education, household members, birth-events and number of under-5 children. Thus the Government of Ethiopia would take immediate steps to address the causes of high unmet need for family planning among women.

Keywords: Complex sampling design, Ethiopia, family planning, Performance Monitoring and Accountability, unmet need DOI: https://dx.doi.org/10.4314/ahs.v17i3.6

Cite as: Workie DL, Zike DT, Fenta HM, Mekonnen MA. A binary logistic regression model with complex sampling design of unmet need for family planning among all women aged (15-49) in Ethiopia. Afri Health Sci. 2017;17(3): 637-646. https://dx.doi.org/10.4314/abs.v17i3.6
\end{abstract}

\section{Background}

Family planning reduces poverty, maternal and child mortality; empowers women by lightening the burden of excessive child bearing and it reduces environmental degradation by stabilizing the population of the planet ${ }^{1-3}$. Millions of women worldwide would prefer to avoid becoming pregnant either right away or never get pregnant, but are not using any contraception ${ }^{4,5}$. Unintended preg-

Corresponding author:

Demeke Lakew Workie,

Department of Statistics,

Bahir Dar University,

Bahir Dar, Ethiopia

Email: demay_gu06@yahoo.com nancy related to unmet need is a worldwide problem that affects women and their families and societies at large $e^{2,6}$. The concept of unmet need indicates the gap between some women's reproductive intentions and their contraceptive behavior for Family Planning $(\mathrm{FP})^{3,4,7}$. Serving all women in low income countries that currently have an unmet need for modern methods would prevent an additional 54 million unintended pregnancies, including 21 million unplanned births, 26 million abortions (of which 16 million would be unsafe) and seven million miscarriages; this would also prevent 79,000 maternal deaths and 1.1 million infant deaths ${ }^{8}$.

Contraception and unmet need levels varied across countries of the world, the lowest contraception and highest
African Health Sciences (a) 2017 Workie et al; licensee African Health Sciences. This is an Open Access article distributed under the termsof the Creative commons Attribution License (https://creativecommons.org/licenses/by/4.0), which permits unrestricted use, distribution, and reproduction in any medium, provided the original work is properly cited. 
unmet need, being in sub-Saharan Africa; $25 \%$ of women of reproductive age who are married or in union have an unmet need for family planning ${ }^{9,10}$. According to Demographic and Health Survey ${ }^{7}$ currently married women unmet need for FP was $22 \%$ for Tanzania and $10 \%$ for Zimbabwe. According to the 2000, 2005 and 2011 Ethiopian demographic and health survey, the level of unmet need for women who are married or in union in Ethiopia was 37, 36 and 25.3\% respectively. The PMA 2020/ Ethiopia survey in round 2 and 3 were 16.2 and 16.5\% of all women in the age group of 15-49 had an unmet need for $\mathrm{FP}^{11}$. In a study conducted in Harare, $33.3 \%$ pregnant women reported that their most recent pregnancies were unintended of which, $50 \%$ had unintended child births and the other $50 \%$ ended with induced abortion $^{12}$. A study conducted in Butajira on determinants of low family planning use showed that unmet need of contraception was $52.4 \%$ of which $74.8 \%$ was attributed to spacing and the rest for limiting ${ }^{8}$. A study conducted in Misha-Southern Ethiopia and Dangila-Amhara region revealed that $26.5 \%{ }^{13}$ and $17.4 \%{ }^{2}$ of married women had unmet need for family planning.

In these studies, no one took into account complex sampling design and fitted the data using binary logistic regression even if this data is from multistage sampling. Therefore fitting such data without considering the survey sampling design may lead to biased estimates of parameters and incorrect variance estimate ${ }^{14}$. For this reason, the current study used the PMA2020/Ethiopia survey data to account for complex sampling design to find the prevalence and key determinants of unmet need for FP among all women aged (15-49) in Ethiopia using binary logistic regression model with complex sampling design.

\section{Methods}

\section{Sampling design, sample size and data course}

The PMA 2020/Ethiopia was conducted in April 2016 at round-4 from 7494 women with two stage-stratified sampling. A sample of 221 enumeration areas (EAs) was drawn by the Central Statistical Agency from its master sampling frame. Each EA was listed and mapped; 35 households were randomly selected. Occupants in selected households were enumerated and eligible women of reproductive age (15-49) were contacted and consented for interview. Data collection was conducted between March and April, 2016 and 7494 women considered in this study. The data collection was led by the Addis Ababa University's School of Public Health at the College of Health Sciences (AAU/SPH/CHS), in collaboration with regional universities, the Federal Ministry of Health and the Central Statistics Agency. Overall direction and support was provided by the Bill \& Melinda Gates Institute for Population and Reproductive Health at the Johns Hopkins Bloomberg School of Public Health. The household and female surveys were carried out by resident enumerators (REs) trained to use smart phones. REs are typically women over the age of 21 and hold a high school diploma or higher level of educational attainment ${ }^{15}$.

\section{Statistical analysis}

Unmet contraceptive need of women defined as women are considered to have an unmet need for spacing or limiting if they are: at risk of becoming pregnant, not using contraception, and either do not want to become pregnant within the next 2 years or are unsure if or when they want to become pregnant or pregnant with a mistimed pregnancy or postpartum amenorrhoeic for up to 2 years following a mistimed birth and not using contraception $^{3,4,8,16}$. Thus, unmet need for family planning was the study variable and coded 1 for unmet need and 0 for no unmet need.

Data was entered into STATA-12 and analyzed using SPSS-21. Binary logistic regression with complex sampling design was fitted for the unmet need outcomes. Married women are disaggregated by various background characteristics to have an insight of their characteristics.

All background characteristics of women used in this study were categorical though the dependent variable, unmet need was binary in nature. Unmet need of contraception with $95 \%$ confidence interval was computed. Bi-variable and multi-variable logistic regression model with complex sampling design were used to identify prevalence and the key determinants of unmet need for FP among all women aged (15-49) in Ethiopia. The binary logistic regression considers that the data are collected using simple random sampling where each sampling unit has the same probability of being chosen from the population. However, if the data is collected using complex survey sampling designs, binary logistic regression may lead to biased estimates of parameters and incorrect variance estimates. This is because, including sampling design when the data was obtained from complex sampling design is better in order to make statistically valid inferences from the finite population ${ }^{14,17}$. Only co-variates that 
were statistically significant at the bi-variable level were included in the multi-variable binary logistic regression to control for confounding. Though many variables were considered in the analysis, only covariates significantly associated with contraception were reported.

\section{Results}

Socio-demographic characteristics of all women aged (15-49) in Ethiopia

Table 1 shows socio-demographic characteristics of 7494 women of reproductive age (15-49) who were recruited for the survey. More than seventy five percent of the respondents were from the rural areas and the majority was in the age group of 15-24 years which contributed 3079 (41.1\%) followed by 25-34 years. Moreover, 3118 (41.6\%) of women were illiterate and $2885(38.5 \%)$ had had primary education. About 4671 (62.3\%) of women were currently married and $613(12.9 \%)$ of them reported that their partner had other wives. Of the study participants, $3242(43.3 \%)$ had no livestock while $4572(61.0 \%)$ had 3-6 members in the house.

\section{Table 1 Socio-demographic characteristics among women aged (15-49) in Ethiopia, March to April, 2016}

\begin{tabular}{|c|c|c|c|}
\hline Variables & & Frequency & Percent \\
\hline & $15-24$ & 3079 & 41.1 \\
\hline Age (5-year groups) & $25-34$ & 2420 & 32.3 \\
\hline & $35+$ & 1995 & 26.6 \\
\hline & Urban & 1803 & 24.1 \\
\hline Place of residence & Rural & 5691 & 75.9 \\
\hline & Never & 3118 & 41.6 \\
\hline & Primary & 2885 & 38.5 \\
\hline Highest level of school attended & Secondary & 1168 & 15.6 \\
\hline & Technical & 202 & 2.7 \\
\hline & Higher & 116 & 1.5 \\
\hline & Currently married & 4671 & 62.3 \\
\hline & Currently living with man & 112 & 1.5 \\
\hline Marital status & Divorced or separated & 515 & 6.9 \\
\hline & Widow & 200 & 2.7 \\
\hline & Never married & 1994 & 26.6 \\
\hline & Poor & 2893 & 38.6 \\
\hline Wealth quintile & Middle & 1440 & 19.2 \\
\hline & Rich & 3161 & 42.2 \\
\hline & $1-2$ & 743 & 9.9 \\
\hline Number of household & $3-6$ & 4572 & 61.0 \\
\hline & $7+$ & 2179 & 29.1 \\
\hline & once & 4508 & 82.0 \\
\hline Married once or more than once & More than once & 989 & 18.0 \\
\hline Partner has other wives & No & 4147 & 87.1 \\
\hline Partner has other wives & Yes & 613 & 12.9 \\
\hline & No & 3242 & 43.3 \\
\hline Livestock on homestead & Yes & 4252 & 56.7 \\
\hline Own livestock & No & 1882 & 25.1 \\
\hline & Yes & 5603 & 74.9 \\
\hline Last baby still alive & No & 178 & 3.5 \\
\hline & Yes & 4853 & 96.5 \\
\hline
\end{tabular}


Prevalence and reason of unmet need for FP among all women aged (15-49) in Ethiopia

Table 2 shows various responses by women of reproductive age (15-49) towards the usage of family planning services. The prevalence of unmet need for FP was $1217(16.2 \%)$ at the time of interview in the study area of Ethiopia. The unmet need for spacing and limiting of births was found to be 768 (10.2) and $449(6.0 \%)$ re- spectively while $2382(31.8 \%)$ of women were not sexually active. The major reason for not using FP among women of reproductive age group was 'not married', not having sex, menopausal/hysterectomy, sub/in fecund, no menses since last birth, breastfeeding and husband away $2821(72.8 \%) ; 440(14.5 \%)$ were fatalistic; some had religious prohibition; $419(13.9 \%)$ were afraid of the side effects and health concerns and $304(10.1 \%)$ had opposition from the partner.

Table 2 Distribution of type of unmet need for FP among women aged (15-49) in Ethiopia, March to April, 2016

\begin{tabular}{|c|c|c|c|}
\hline & & Frequency & Percent \\
\hline \multirow{8}{*}{ Unmet need } & Missing & 4 & 0.1 \\
\hline & Not sexually active & 2382 & 31.8 \\
\hline & Unmet need for spacing & 768 & 10.2 \\
\hline & Unmet need for limiting & 449 & 6.0 \\
\hline & Using for spacing & 1317 & 17.6 \\
\hline & Using for limiting & 769 & 10.3 \\
\hline & No unmet need & 1085 & 14.5 \\
\hline & In fecund or menopausal & 719 & 9.6 \\
\hline \multicolumn{4}{|c|}{ Prevalence of unmet need of FP $(7,494)$} \\
\hline \multirow{2}{*}{ Total unmet need } & no unmet need & 6277 & 83.8 \\
\hline & unmet need (spacing and/or limiting) & 1217 & 16.2 \\
\hline \multirow{9}{*}{ Reason not using FP*: } & No Need ${ }^{\mathrm{a}}$ & 2821 & 72.8 \\
\hline & up to god/fatalistic or religious prohibition & 440 & 14.5 \\
\hline & Oposed $^{\mathrm{b}}$ & 304 & 10.1 \\
\hline & knows no method and Source & 81 & 2.7 \\
\hline & fear of side effects or health concerns & 419 & 13.9 \\
\hline & lack of access/too far or costs too much & 35 & 1.2 \\
\hline & $\begin{array}{l}\text { preferred method not available or no method } \\
\text { available }\end{array}$ & 29 & 0.9 \\
\hline & inconvenient to use & 29 & 0.9 \\
\hline & other & 545 & 18.0 \\
\hline
\end{tabular}

${ }^{*}$ multiple responses. ${ }^{a}$ not married, not having sex, menopausal/hysterectomy, sub/infecund, no menses since last birth, breastfeeding and husband away. Among this all the majority 1714(36.2\%) was not married. ${ }^{b}$ opposed by partner, respondent, others or interferes with other body.

Family planning methods used and exposure among all women aged (15-49) in Ethiopia

Table 3 revealed that various responses by women of reproductive age (15-49) towards the most effective current FP methods. Among all women of reproductive age, only $1343(17.9 \%)$ and $1246(35.3 \%)$ reported that they were visited by a health worker and talked to about FP in last 12 months respectively. In this study, 5062 (67.8 $\%)$ women reported that they had heard information about family planning from different sources within the 
last 12 months. The most frequently used source of information for family planning was radio 2655 (52.4\%), television 1836 (36.3\%) and newspaper 571 (11.3\%). In this study, $4416(81.7 \%)$ of women knew a place to obtain a method of FP and $33.4 \%$ of women were using most effective current FP method. The favorite modern contraceptive ever practiced among women of reproductive age was injectable that is $1254(60.4 \%)$ and the least was beads which constituted $3(0.1 \%)$. Among FP users, $1160(48.5 \%)$ of women obtained FP from governmental health center; and 738 (30.9\%) obtained FP were from a governmental health post when they started.

Table 3 Most effective current FP method among women aged (15-49) in Ethiopia, March to April, 2016

\begin{tabular}{|c|c|c|c|}
\hline \multicolumn{2}{|c|}{ Variables } & \multirow{2}{*}{$\frac{\text { Frequency }}{15}$} & \multirow{2}{*}{$\frac{\text { Percent }}{0.7}$} \\
\hline \multirow{12}{*}{ Most effective current FP method } & Female sterilization & & \\
\hline & Implants & 477 & 23.0 \\
\hline & IUD & 42 & 2.0 \\
\hline & Injectables & 1254 & 60.4 \\
\hline & Pill & 143 & 6.9 \\
\hline & Emergency & 11 & 0.5 \\
\hline & Male condoms & 27 & 1.3 \\
\hline & Beads & 3 & 0.1 \\
\hline & LAM & 12 & 0.6 \\
\hline & Rhythm & 78 & 3.8 \\
\hline & Withdrawal & 13 & 0.6 \\
\hline & Other traditional & 2 & 0.1 \\
\hline \multirow{2}{*}{$\begin{array}{c}\text { Do you know a place you can obtain } \\
\text { a method of FP }\end{array}$} & No & 992 & 18.3 \\
\hline & Yes & 4416 & 81.7 \\
\hline \multirow{6}{*}{$\begin{array}{l}\text { Did you obtain the method you } \\
\text { wanted? }\end{array}$} & No & 187 & 7.5 \\
\hline & Yes & 2304 & 92.5 \\
\hline & Governmental hospital & 98 & 4.1 \\
\hline & Governmental health center & 1160 & 48.5 \\
\hline & Governmental health post & 738 & 30.9 \\
\hline & NGO & 17 & 0.7 \\
\hline \multirow{7}{*}{$\begin{array}{l}\text { Where did you obtain method when } \\
\text { you started using }\end{array}$} & Volunteer & 2 & 0.1 \\
\hline & FP clinic & 32 & 1.3 \\
\hline & Private hospital & 223 & 9.3 \\
\hline & Pharmacy & 94 & 3.9 \\
\hline & Shop & 3 & 0.1 \\
\hline & Friend relative & 12 & 0.5 \\
\hline & Other & 11 & 0.5 \\
\hline Visited by health worker about FP & No & 6139 & 82.1 \\
\hline last 12 months & Yes & 1343 & 17.9 \\
\hline \multirow{2}{*}{$\begin{array}{l}\text { Visited health facility in last } 12 \\
\text { months }\end{array}$} & No & 3961 & 52.9 \\
\hline & Yes & 3527 & 47.1 \\
\hline \multirow{3}{*}{ Talked to about FP at health facility } & No & 2280 & 64.7 \\
\hline & Yes & 1246 & 35.3 \\
\hline & Radio & 2655 & 52.4 \\
\hline \multirow[t]{2}{*}{ Exposure to Media* } & Television & 1836 & 36.3 \\
\hline & Newspaper & 571 & 11.3 \\
\hline
\end{tabular}

*multiple responses.

Among women who participated in this study, the smallest unmet need was from Addis Ababa 12(3.2\%) followed by Dire Dawa 2(8\%) and Amhara 157 (9.2\%) regions whereas women who had highest unmet need were from
Benishangul Gumuz 28(26.4\%), Oromia 644(22.4\%) and Harari 4(18.2\%). The prevalence of unmet need for FP in SNNPR 1681(16.2\%) was similar with the national results (Table 4). 
Table 4: Total unmet need for FP by region in Ethiopia, 2016

\begin{tabular}{llll}
\hline & & \multicolumn{2}{l}{ Total unmet need } \\
\cline { 2 - 4 } & & No unmet & Unmet \\
\hline Tigray & Count $(\%)$ & $429(86.0)$ & $70(14.0)$ \\
Afar & Count $(\%)$ & $78(84.8)$ & $14(15.2)$ \\
Amhara & Count $(\%)$ & $1544(90.8)$ & $157(9.2)$ \\
Oromiya & Count $(\%)$ & $2233(77.6)$ & $644(22.4)$ \\
Ethiopia Somali & Count $(\%)$ & $67(89.3)$ & $8(10.7)$ \\
BenishangulGumuz & Count $(\%)$ & $78(73.6)$ & $28(26.4)$ \\
SNNPR & Count $(\%)$ & $1409(83.8)$ & $272(16.2)$ \\
Gambella & Count $(\%)$ & $32(86.5)$ & $5(13.5)$ \\
Harari & Count $(\%)$ & $18(81.8)$ & $4(18.2)$ \\
Addis Ababa & Count $(\%)$ & $366(96.8)$ & $12(3.2)$ \\
Dire Dawa & Count $(\%)$ & $23(92.0)$ & $2(8.0)$ \\
Total & Count $(\%)$ & $6277(83.8)$ & $1216(16.2)$ \\
\hline
\end{tabular}

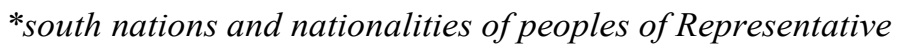

Factors associated with unmet need for FP among all women aged (15-49) in Ethiopia

Table 5 shows the bi-variable and multi-variable factors associated with unmet need for FP among women of reproductive age group in Ethiopia. After controlling for the possible confounders using forward stepwise likelihood ratio method, age, marital status, number of household members, birth events, number of children under five, place of residence, highest level of school attended and knew a place of FP method were found as significantly associated factors for the unmet need for FP. 


\section{Table 5 Factors associated with unmet need for FP among aged (15-49) in Ethiopia, March to April, 2016}

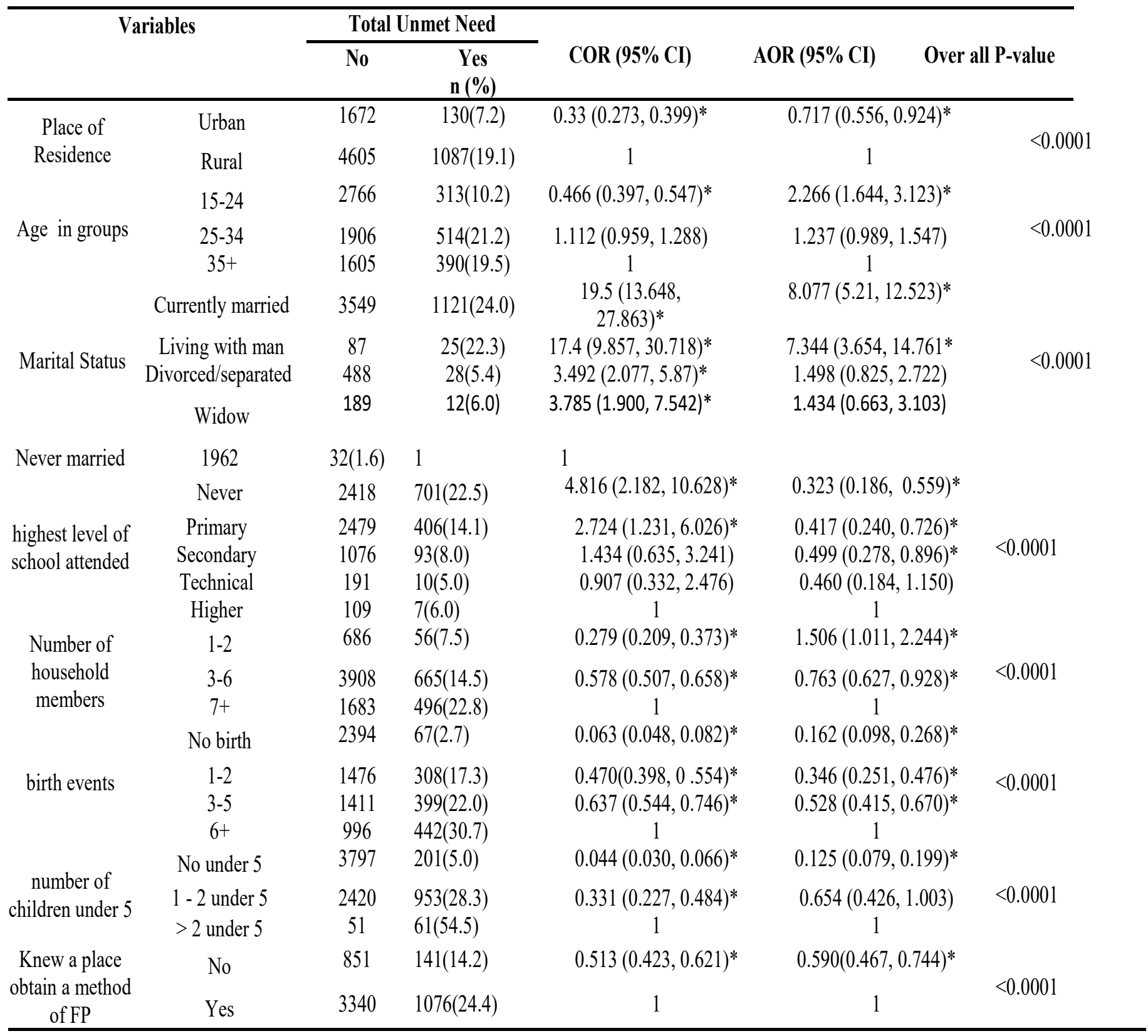

Keys: COR (Crude odds ratio); AOR (Adjusted Odds Ratio); CI (Confidence Interval);

1 (Reference Category); *Odds Ratio is a significant at $\alpha=0.05$

\section{Discussion}

This paper was conducted to investigate the magnitude and determinants of unmet need for FP among all women of reproductive age group. In this paper, we also aimed at finding out the determinants of unmet need for FP in the community. Of the 7494 women of reproductive age group, $1217(16.2 \%)$ had an unmet need for FP
$10.2 \%$ for spacing and $6 \%$ for limiting. There is a clear relationship between women's age and the level of unmet need. Unmet need is typically low in women of age 15-24 and peaks for many women in their thirties and then declines in the forties. It is perhaps the experience and awareness about contraception among older women that reduces the likelihood of unmet need among them. 
In addition, the country's five-year Growth and Transformation Plan (GTP) works to gender equality empower all women and girls and eliminate early marriage ${ }^{18}$. The level of unmet need for FP in this study $(16.2 \%)$ is lower than the study conducted on currently married women at Dangila $(17.4 \%)^{9}$ but seemed steady with the PMA 2020/ Ethiopia survey of all women of reproductive age group in round 2 and $3(16.2 \text { and } 16.5 \%)^{11}$. This may need more commitment of the Ethiopian government and NGO to achieve a $3.7 \%$ unmet need for FP by $2030^{18}$.

Relatively lower unmet need among urban women in Ethiopia could be ascribed to accessibility of health services and awareness of the urbanites on family planning methods. Better mass media coverage in urban compared to rural areas might have increased knowledge and practice. Urban women could also be more enlightened and autonomous to utilize health services compared to their counterparts in rural areas ${ }^{9,19}$.

Women's educational status is positively associated with contraceptive prevalence in Ethiopia. Studies elsewhere revealed a similar pattern of relationship between educational status and maternal health service including family planning utilization ${ }^{9,20}$. Highest level of school attended could probably give women better chance to understand uses of contraception to reduce fertility, maternal and child morbidity and mortality. Women who attended higher level of school could avoid the negative effects of family planning methods by reading different publications about it and getting appropriate advice from a service provider thereby increased their consistent use.

Number of birth events among women is also positively associated with contraceptive prevalence in Ethiopia. As the number of events increased there is less unmet need for FP in Ethiopia. Meanwhile, women who had no under-five child were less likely to have unmet need for FP compared to those who had more than two under five. This finding was in line with a study conducted in Mojo town, Enemay, East Gojjam Zone and Bihar, India 3,9, 21,22. Women who had more births avoided the negative effects of family planning methods by reading different publications about the side effect of contraception methods and getting appropriate advice from a service provider thereby increased their consistent use.

\section{Conclusion}

This study was aimed to make a contribution to identify the prevalence and key determinants of unmet need by using a binary logistic regression model with complex sampling design to account for the complexity of the survey. The key determinants of unmet need for FP in Ethiopia were place of residence, age of women, marital status, highest level of school attended, number of household members, birth events, number of children under five and knew a place from which to obtain a method of FP. The influence of these factors can be used to develop the strategies of reducing unmet need FP in Ethiopia.

The unmet need in Ethiopia is still very high, especially in currently married women. A high rate of unmet need for modern contraceptive methods might potentially lead to increased rates of unwanted pregnancies and induced abortions. Thus the Government of Ethiopia will have to take immediate steps to address the causes of high unmet need for family planning among women.

\section{List of Abbreviations}

AAU: Addis Ababa University, AOR: Adjusted Odds Ratio, CHS: College of Health Sciences, CI: Confidence Interval, COR: Crude Odds Ratio, EDHS: Ethiopia Demographics Health Survey, ESA: Ethiopian Statistical Agency, FP: Family Planning, GTP: Growth and Transformation Plan, LAM: Lactational Amenorrhea Method, OR: odds Ratio, PMA2020: Performance Monitoring and Accountability 2020, REs: Resident Enumerators, SAS: Statistical Analysis System, SD: standard Deviation, SPH: School of Public Health, SPSS: statistical packages for social Sciences.

\section{Ethics approval and consent to participate}

It is not applicable, because the data was collected by performance monitoring and accountability 2020 (PMA2020)/Ethiopia survey project.

\section{Consent for publication}

Participants were made aware in the consent form that the results of the study would be published but that no data would be presented to allow the identification of individuals.

\section{Availability of data and materials}

The dataset supporting the conclusions of this article 
is held by PMA2020/Ethiopia Survey Project and the de-identified data may be made available based on written request and approval by PMA 2020's coordinating center in Baltimore.

\section{Competing interests}

The authors declare that they have no conflict of interests.

\section{Funding}

The data collection funding was provided by the Bill \& Melinda Gates Foundation. No additional funding was sought to complete this article.

\section{Authors' contributions}

MA supervised the data collection. DL analyzed the data and wrote the manuscript. MA, DT and HM critically edited the manuscript. All authors read and approved the final manuscript.

\section{Acknowledgements}

The authors are indebted to Selamawit Desta, MSPH, MIA, Program Officer, PMA 2020 who gave us permission access to PMA2020/Ethiopia dataset.

\section{References}

1. Kavanaugh ML, Anderson RM. Contraception and beyond: The health benefits of services provided at family planning centers. New York: Guttmacher Institute; 2013, http://www.guttmacher.org/ pubs/health-benefits.pdf.

2. Robinson N, Stoffel C, Haider S. Global women's health is more than maternal health: a review of gynecology care needs in low-resource settings. Obstetrical \& gynecological survey. 2015;70(3):211-22, doi: 10.1097/ OGX.0000000000000166.

3. Genet E, Abeje G, Ejigu T. Determinants of unmet need for family planning among currently married women in Dangila town administration, Awi Zone, Amhara regional state; a cross sectional study. Reproductive health. 2015;12(1):42 PubMed, doi: 10.1186/s12978-015-00383.

4. Casterline JB, Sinding SW. Unmet need for family planning in developing countries and implications for population policy. Population and development review. 2000;26(4):691723.

5. Bhattathiry MM, Ethirajan N. Unmet need for family planning among married women of reproductive age group in urban Tamil Nadu. Journal of Family and Community medicine. 2014;21(1):53, doi: 10.4103/2230-8229.128786.

6. Sedgh G, Singh S, Hussain R. Intended and unintended pregnancies worldwide in 2012 and recent trends. Studies in family planning. 2014;45(3):301-14.

7. EDHS. Key indicators report for Ethiopia demographic and health survey: the DHS program ICF Rockville, Maryland, USA. . Report. Ethiopia: 2016.

8. Singh S, Darroch JE. Adding it up: Costs and benefits of contraceptive services. Guttmacher Institute and UNFPA. 2012, http://www. guttmacher.org/pubs/ AIU-2012-estimates.pdf.

9. Mekonnen W, Worku A. Determinants of fertility in rural Ethiopia: the case of Butajira Demographic Surveillance System (DSS). BMC Public Health. 2011;11(1):782, doi: 10.1186/1471-2458-11-782.

10. Moreland S SE, Sharma S, . World population prosepects and unmet need for family planning. Futures Group: Washington. 2010.

11. AAU/SPH. Key family planning indicators of pma2016/Ethiopia-R4:. Performance Monitoring and Accountability 2020 (PMA2020) Survey. 2016. Ethiopia and Baltimore, Maryland, USA. 2016.

12. Worku S, Fantahun M. Unintended pregnancy and induced abortion in a town with accessible family planning services: The case of Harare in Eastern Ethiopia. Ethiopian Journal of Health Development. 2006;20(2):79-83.

13. Chafo K DF. Unmet Need for Family Planning and Associated Factors among Currently Married Women in Misha District, Southern Ethiopia: A Cross Sectional Study. J Women's Health Care 2014;3(165), http://dx.doi. org/10.4172/2167-0420.1000165.

14. Liu X, Koirala H. Fitting proportional odds models to educational data with complex sampling designs in ordinal logistic regression. Journal of Modern Applied Statistical Methods. 2013;12(1):26, http://digitalcommons.wayne. edu/jmasm/vol12/iss1/26.

15. Performance Monitoring and Accountability 2020 (PMA2020) Survey. 2016. Ethiopia and Baltimore, Maryland, USA. [Internet]. 2016. Available from: https:// www.dropbox.com/s/yphzhwyvq62617k/PMA2016_ ETR4_HHQFQ_15Dec2016.zip?dl=0

16. Chandra-Mouli, Sharon J Phillips, Nancy E Williamson and Gwyn Hainsworth. Contraception for adolescents in low and middle income countries: needs, barriers, and access. Reproductive Health 2014 11(1), doi: 10.1186/1742-4755-11-1. 
17. Habyarimana F, Zewotir T, Ramroop S. A proportional odds model with complex sampling design to identify key determinants of malnutrition of children under five years in Rwanda. Mediterranean Journal of Social Sciences. 2014;5(23):1642, doi: 10.5901/mjss.2014.v5n23p1642. 18. EPA. National Report of Ethiopia, the United Nations Conference on Sustainable Development (Rio+20). In: Ethiopia FDRo, editor. Addis Ababa 2012. 19. Fantahun M, Berhane Y, Högberg U, Wall S, Byass P. Young adult and middle age mortality in Butajira demographic surveillance site, Ethiopia: lifestyle, gender and household economy. BMC public Health. 2008;8(1):268 PubMed, doi:10.1186/1471-2458-8-268.
20. Babalola S, Fatusi A. Determinants of use of maternal health services in Nigeria-looking beyond individual and household factors. BMC pregnancy and childbirth. 2009;9(1):43, doi: 10.1186/1471-2393-9-43.

21. Dejenu G, Ayichiluhm M, Alemu A. Prevalence and Associated Factors of Unmet need for Family Planning among Married Women in Enemay District, Northwest Ethiopia: A Comparative Cross-Sectional Study. Global J Med Res. 2013;13(4).

22. Gizaw A, Regassa N. Family planning service utilization in Mojo town, Ethiopia: A population based study. Journal of Geography and Regional Planning. 2011;4(6):355. 